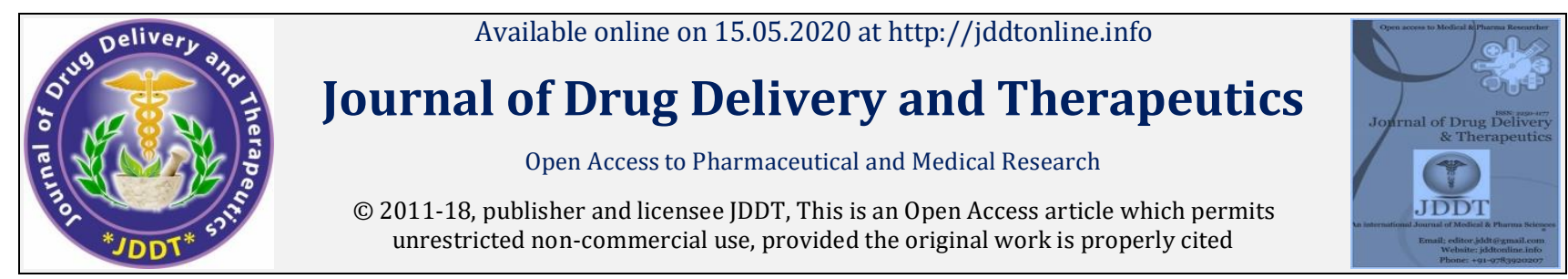

Open $\odot$ Access

Research Article

\title{
Assessment of Self-Care Practices among Type 2 Diabetic Patients in a Secondary Care Teaching Hospital
}

\author{
K P Athira, K Faheem Iqbal, V Jasna, *Jeeba Chinnappan, Purnima Ashok, Rini Susan Varghese \\ Department of Pharmacy Practice, K.L.E College of Pharmacy, Bengaluru-10, Karnataka, India
}

\begin{abstract}
Background: Diabetes is one of the major health problems worldwide that can be effectively managed by good self-care activities like medication adherence, exercise, monitoring of blood glucose, foot care and diet. Objectives: The study assessed the self-care activities of diabetic patients using summary of diabetes self-care activities scale (SDSCA) and the variables (Age, gender, educational level, socioeconomic status (SES)) associated with it. Methods: A cross-sectional descriptive study was undertaken in 400 Type 2 diabetic patients. Self-care practices of the patients were evaluated by using SDSCA and correlation with variables were determined statistically. Results: Among 400 diabetic patients about 215 (53.75\%) had an average score of self-care. Self-care was poor in 184 (46\%) subjects, and only 1 subject ( $0.25 \%)$ scored good. Blood sugar monitoring was the highest (100\%) followed by medication adherence (92.75\%) whereas inadequate levels of selfcare were reported in foot care (1.5\%), and physical activity (31.5\%) domains. A significant positive correlation was found between self-care practices and socio-demographic variables such as age $(r=0.298, p=0.000)$, income $(r=0.490, p=0.000)$ occupation $(r=0.433, p=0.000)$, education $(r=0.582, p=0.000)$, and Socio-Economic status $(r=0.599, p=0.000)$. Conclusion: The study revealed higher level of adherence to selfcare activities in terms of blood sugar monitoring and medication taking behaviour in the current setting, but self-care in other domains such as foot care is critically low. Age, education and Socio-Economic status seems to affect the self-care practice by the patients.
\end{abstract}

Keywords: Diabetes, Diabetes self- care, Diabetic foot care, Summary of diabetes self-care activities (SDSCA) score.

Article Info: Received 12 March 2020; Review Completed 23 April 2020; Accepted 30 April 2020; Available online 15 May 2020

Cite this article as:

Athira KP, Faheem IK, Jasna V, Chinnappan J, Ashok P, Varghese RS, Assessment of Self-Care Practices Among Type 2 Diabetic Patients in a Secondary Care Teaching Hospital, Journal of Drug Delivery and Therapeutics. 2020; 10(3):119-124 http://dx.doi.org/10.22270/jddt.v10i3.4098

*Address for Correspondence:

Jeeba Chinnappan, Department of Pharmacy Practice, K.L.E College of Pharmacy, Bengaluru-10, Karnataka, India

\section{INTRODUCTION}

Diabetes mellitus (DM) is a metabolic disorder which is characterised by the presence of chronic hyperglycaemia with disturbance of protein, fat, and carbohydrate, metabolism [1]. According to WHO at least 285 million people are already affected with DM and it is the major reason for 3.2 million deaths, six deaths every minute and 8700 every day and it is said that this number will increase by $42 \%$ in developing countries and by $70 \%$ in developed countries by 2030 [2]. Exclusive of increased health care cost and morbidities diabetes is allied with many fatal life-threatening complications such as microvascular, macrovascular and combination of both. These complications include diabetic retinopathy, nephropathy, peripheral neuropathy, cardiovascular diseases, diabetic foot and peripheral artery disease [3]. The primary objective in the management of diabetes is to avert or minimise chronic diabetic complications [4]. Non pharmacological treatment is a fundamental element of diabetes care and includes selfmanagement, medical nutrition therapy (MNT), smoking cessation, physical activity and psychosocial support. With the help of health care practitioners diabetic patients should concentrate more on how to enhance lifestyle modifications throughout the different stages of disease in order to ISSN: 2250-1177

[119] augment diabetes care[5]. Diabetes can be controlled by a combination of five different activities such as diet modification, education, physical activity and exercise, medication adherence, and discipline. A diabetic will need to take a nutritionally well balanced diet with some regulations to maintain health. The goal is to keep the body healthy and to maintain blood glucose level within the normal range. It is vital for all diabetic and their family members to learn about the illness and help to support the diabetic in making several life style changes that are required of him/her. The American diabetes association recommends that adult diabetic patients should involve in two and half hours or more of physical activity weekly, for at least 3 days a week, with no more than two consecutive days with no activity[5]. Exercise or physical work is very important in controlling diabetes. It relieves stiffness of limb and muscle and help enhancing circulation of blood. It enhances action of insulin and stimulates insulin secretion[6]. Patient's adherence to their anti-diabetic medications is a demanding and essential factor to avert troublesome complications and to minimize the health care resource utilizations ${ }^{[7]}$. One of the major barrier to effective DM management which contribute suboptimal blood glucose control is poor treatment adherence[8]. Poor medication adherence can have adverse consequences for the provider, 
the physician, the patients and the stability of the health care system [9]. Medication adherence is a crucial factor to attain optimal diabetes control and to prevent morbidity and mortality[10]. Successful management of diabetes even under the most ideal circumstances requires great discipline ${ }^{[11]}$. It is the key to diabetes management. A diabetic must maintain discipline during his /her entire life[6]. Diabetes is a persistent lifestyle disease, which requires lifelong commitment. Hence it is imperative to promote self-care practices among diabetics, as these practices help in minimising or delaying the complications of diabetes. Selfcare in DM is a transformative process which helps in developing awareness and knowledge by learning to live with the complex nature of the DM in a social context. Selfcare practices include proper eating practice, regular exercise, medication adherence, a regular medical follow up, regular blood sugar level checking and other blood parameters, fundus examination, daily self-foot examination and regular ECG monitoring[12]. Diabetes self-care requires life style modifications along with the support of health care practitioner to achieve a greater level of self-confidence to lead a successful behaviour change[13]. Diabetic complications can be developed due to poor self-care knowledge and poor long term metabolic control[14]. Selfmanagement need procurement of skill and knowledge necessary to conveniently engage in a complex set of behaviours aimed at managing health, such as medication adjustment and self-monitoring, in the context of daily living [15].

\section{MATERIALS AND METHODS}

A cross - sectional descriptive study was conducted at the out- patient department of KC general hospital Malleswaram, Bangalore from September 2018 to February 2019. All diabetic patients of age $>20$ years of either gender, who are on anti-diabetic drugs for at least one year were included. While diabetic inpatients, patients with gestational diabetes, too ill to be interviewed, patients with psychiatric disorder and who refused to participate in the study were excluded. The objectives of the study were described to the participants and an informed written and signed consent was collected in Kannada. Data collecting tools included modified patient profile form , Modified Kuppuswamy socioeconomic scale) and SDSCA questionnaire. Socio-economic status of the participants was calculated using Modified Kuppuswamy scale. Summary of Diabetic Self-care Activity Scale developed by Toobert and collegues [16] in the year of 1999 in US was used to assess self-care practices of the patients. It is a self-report questionnaire of DM self- management that consist of five elements of diabetes care such as: foot care, blood sugar monitoring, general diet, physical activity and medication adherence during the past seven days. The instrument which was originally written in English was translated into local language (Kannada) and back-translated to English by a person who is not related with this study for appropriateness of the translation. This questionnaire measured five domains. In the diet domain, there are five questions such as, frequency of consuming fat rich foods, frequency of consuming fruits and vegetables, frequency of following a healthful eating plan, and frequency of spacing carbohydrates evenly through the day. The physical activity domain included questions regarding work related and leisure- time physical activity. Similarly monitoring of blood sugar level domain consists of two questions regarding self-monitoring of blood sugar levels over the past seven days and also performing selfmonitoring of blood sugar levels according to the advice of health care provider. Foot care domain covers questions regarding soaking of feet, washing of feet, drying in between the toes, inspection of feet daily and inspecting sandals or shoes every day. Medication adherence domain contains questions related to consumption of prescribed oral hypoglycaemic drugs and insulin administration. Self-care activities in each domain were scored from 0 to 7 . Except soaking of feet and intake of fat rich foods all the other questions were positively scored. In the diet domain; if a patient had adhered to self-care activities for more than $75 \%$ in a week, satisfactory self-care will be achieved. Similar scoring methods were used for foot care domain. The exercise domain was said to be satisfactory only if the patient had performed free-time and work related physical activity for at least 20 minutes at least for 5 days in a week. If a patient doesn't perform self-monitoring of blood sugar in the past three months this domain would be considered as unsatisfactory. The medication taking behaviour of the population was considered satisfactory, if the patient adhered to prescribed medications for six days of a week. Spearman's coefficient of correlation was used to find out the correlation between SDSCA score and variables.

\section{RESULTS}

A total of 400 patients were assessed for diabetic self-care activities during the study period. Males comprised approximately $56.75 \%$ (227) of the sample. About 123 $(30.75 \%)$ of the study participants were in the age group of $55-64$ years and the mean age of patients was $56.03 \pm 11.79$ years. Demographic details of the diabetics are depicted in Table No.1.

Table 1: Socio-demographic characteristics of patients $(\mathrm{N}=400)$

\begin{tabular}{|c|c|c|c|}
\hline SI No. & Domains & Variables & Percentage of patients (Number of patients) \\
\hline \multirow[t]{6}{*}{1} & \multirow[t]{6}{*}{ Age group } & $15-24$ & \\
\hline & & $25-34$ & $3 \%(12)$ \\
\hline & & $35-44$ & $15.7 \%(63)$ \\
\hline & & $45-54$ & $24.5 \%(98)$ \\
\hline & & $55-64$ & $30.75 \%(123)$ \\
\hline & & $\geq 65$ & $26 \%(104)$ \\
\hline \multirow[t]{2}{*}{2} & \multirow[t]{2}{*}{ Gender } & Male & $56.75 \%(227)$ \\
\hline & & Female & $43.25 \%(173)$ \\
\hline \multirow[t]{2}{*}{3} & \multirow[t]{2}{*}{ Marital status } & Single & $2.5 \%(10)$ \\
\hline & & Married & $97.5 \%(390)$ \\
\hline \multirow[t]{4}{*}{4} & \multirow[t]{4}{*}{ Psychosocial habits } & Smoking & $5.25 \%(21)$ \\
\hline & & Alcoholic & $4.5 \%(18)$ \\
\hline & & Both & $6.75 \%(27)$ \\
\hline & & Nil & $83.5 \%(334)$ \\
\hline
\end{tabular}


Table 1(Continues): Socio-demographic characteristics of patients $(\mathrm{N}=400)$

\begin{tabular}{|c|c|c|c|}
\hline SI. no & Domains & Variables & Percentage of patients (no. of patients) \\
\hline \multirow[t]{7}{*}{5} & \multirow[t]{7}{*}{ Educational status } & Illiterate & $28.5 \%(114)$ \\
\hline & & $1^{\text {st }}-4^{\text {th }}$ std & $12.5 \%(50)$ \\
\hline & & $5^{\text {th- }} 7^{\text {th }}$ std & $15 \%(72)$ \\
\hline & & $8^{\text {th- }-10^{\text {th }} \text { std }}$ & $28.25 \%(113)$ \\
\hline & & $11^{\text {th }}-12^{\text {th }}$ std/ diploma & $7.25 \%(29)$ \\
\hline & & PG/UG & $5.5 \%(22)$ \\
\hline & & Profession/ honours & - \\
\hline \multirow[t]{5}{*}{6} & \multirow[t]{5}{*}{$\begin{array}{l}\text { Socio-economic } \\
\text { status (Modified } \\
\text { Kuppuswamy scale) }\end{array}$} & Upper & - \\
\hline & & Upper middle & $1.75 \%(7)$ \\
\hline & & Lower middle & $12 \%(48)$ \\
\hline & & Upper lower & $62.25 \%(249)$ \\
\hline & & Lower & $24 \%(96)$ \\
\hline
\end{tabular}

\section{Analysis of self-care activities}

\section{Total score}

When the total self-care of the subjects was calculated it was found that, the majority (53.75\%) of diabetic patients had an average score of self-care. Total self-care scores are shown in figure1. Table No.2 depicts the distribution of total score among different socio-economic class (Using Modified Kuppuswamy socio-economic scale 2018). 1 (0.25\%) participant who scored good belonged to the lower-middle class. $140(35 \%)$ respondents from upper-lower class scored average.

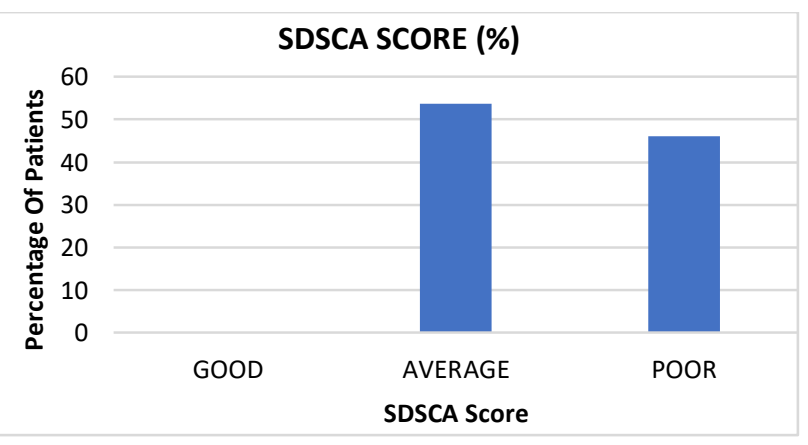

Figure 1: SDSCA Score distribution $(\mathrm{N}=400)$

Table 2: SDSCA Score according to Socio-economic status $(\mathrm{N}=400)$

\begin{tabular}{|l|l|l|l|}
\hline Socio-economic status & $\begin{array}{l}\text { Good } \\
\text { (Number of patients) }\end{array}$ & $\begin{array}{l}\text { Average } \\
\text { (Number of patients) }\end{array}$ & $\begin{array}{l}\text { Poor } \\
\text { (Number of patients) }\end{array}$ \\
\hline Upper & - & - & - \\
\hline Upper-middle & - & $1 \%(4)$ & $0.75 \%(3)$ \\
\hline Lower-middle & $0.25 \%(1)$ & $7.25 \%(29)$ & $4.5 \%(18)$ \\
\hline Upper-lower & - & $35 \%(140)$ & $27.25 \%(109)$ \\
\hline Lower & - & $10.5 \%(42)$ & $13.5 \%(54)$ \\
\hline
\end{tabular}

\section{Domain wise assessment of self-care activities}

Good dietary behaviour was present in only 152 (38\%) participants. $274(68.5 \%)$ participants did not practice recommended level of physical activity in the past week. As shown in Table 3 all the patients monitored their glycaemic level at least once in the past three months. Foot care was the least identified self-care activity by the patients. Only 6 $(1.5 \%)$ subjects examined their feet at regular intervals whereas $394(98.5 \%)$ participants scored poor in the foot care domain. 371(92.75\%) participants were adherent to the recommended antidiabetic medications.

Table 3: Domain-wise self-care practices $(\mathrm{N}=400)$

\begin{tabular}{|l|l|l|l|}
\hline SI No & Domain & $\begin{array}{l}\text { Satisfactory } \\
\text { (Number of patients) }\end{array}$ & $\begin{array}{l}\text { Non-satisfactory } \\
\text { (Number of patients) }\end{array}$ \\
\hline 1 & Diet & $38 \%(152)$ & $62 \%(248)$ \\
\hline 2 & Foot care & $1.5 \%(6)$ & $98.5 \%(394)$ \\
\hline 3 & Physical activity & $31.5 \%(126)$ & $68.5 \%(274)$ \\
\hline 4 & Blood sugar monitoring & $100 \%(400)$ & - \\
\hline 5 & Medication & $92.75 \%(371)$ & $7.25 \%(29)$ \\
\hline
\end{tabular}




\section{Statistical analysis}

Spearman's coefficient of correlation was done to examine the association between diabetes self-care activities with socio-demographic variables such as age, gender, marital status, education, occupation, income, socio-economic status and duration of diabetes. The data were analysed using SPSS version 17. The results from the analysis as given in Table 4 shows that the total self-care practice score was found to have a significant positive correlation with age $(\mathrm{r}=0.298, \mathrm{p}=$ $0.000)$, education $(\mathrm{r}=0.582, \mathrm{p}=0.000)$, occupation $(\mathrm{r}=0.433$, $\mathrm{p}=0.000)$, income $(\mathrm{r}=0.490, \mathrm{p}=0.000)$, and socio-economic status $(\mathrm{r}=0.599, \mathrm{p}=0.000)$.

Table 4: Correlation of self-care practices with variables $(\mathrm{N}=400)$

\begin{tabular}{|l|l|l|l|l|l|l|}
\hline & Age & Gender & $\begin{array}{l}\text { Marital } \\
\text { status }\end{array}$ & Education & Occupation & Income \\
\hline Total & $0.298^{* *}$ & $-0.157^{* *}$ & 0.056 & $0.582^{* *}$ & $0.433^{* *}$ & $0.490^{* *}$ \\
score & 0.000 & 0.002 & 0.267 & 0.000 & 0.000 & 0.000 \\
\hline & Smoking & Alcohol & None & Both & SES status & Family history \\
\hline Total & $-0.211^{* *}$ & -0.001 & $0.116^{*}$ & 0.017 & $0.599^{* *}$ & $0.197^{* *}$ \\
score & 0.000 & 0.977 & 0.020 & 0.736 & 0.000 & 0.000 \\
\hline
\end{tabular}

\section{Domain-wise total score}

Correlation between domain-wise total score and study variables showed a significant positive correlation between diet total score and education $(\mathrm{r}=0.126, \mathrm{p}=0.012)$, socioeconomic status ( $\mathrm{r}=0.143, \mathrm{p}=0.004)$ whereas age, gender, marital status, duration of DM had no significant correlation.
A significant positive correlation ( $r=0.135,0.007)$ existed between total foot care score and education but there were no correlation with respect to age, gender, marital status, SES and duration of DM. Adherence to medication had no correlation with any of the above mentioned study variables (Table No.5).

Table 5: Domain-wise correlation of self-care practices with variables $(\mathrm{N}=400)$

\begin{tabular}{|l|l|l|l|l|l|l|}
\hline & Age & Gender & Marital status & Duration of DM & Education & SES \\
\hline Diet & 0.087 & 0.045 & -0.033 & 0.036 & $0.126^{*}$ & $0.143^{* *}$ \\
& 0.082 & 0.0364 & 0.509 & 0.469 & 0.012 & 0.004 \\
\hline Foot care & 0.046 & 0.054 & -0.033 & 0.018 & $0.135^{* *}$ & -0.098 \\
& 0.356 & 0.279 & 0.506 & 0.727 & 0.007 & 0.051 \\
\hline Medication & 0.042 & 0.058 & -0.019 & 0.007 & -0.043 & 0.041 \\
& 0.403 & 0.245 & 0.706 & 0.895 & 0.394 & 0.416 \\
\hline Exercise & 0.000 & 0.000 & $-0.573^{*}$ & $-0.967^{* *}$ & $0.777^{*}$ & $-0.577^{*}$ \\
& 1.000 & 1.000 & 0.028 & 0.002 & 0.014 & 0.028 \\
\hline
\end{tabular}

\section{DISCUSSION}

In this study among 400 type 2 diabetes patients only $0.25 \%$ were having good self-care practices, while majority of the patients $(53.75 \%)$ had average score for self-care which was inconsistent with the study conducted by Nazila et al where they found that majority of patients $(63.6 \%)$ had poor selfcare score due to inadequate blood sugar testing, irregular medication intake and lack of physical activity[17]. In the present study population $46 \%$ had a poor self-care score this poor score was attributed to various reasons like lack of family support, poor knowledge, lack of time, financial constraints, age related problems, sedentary work as given by patients upon interview. Medication adherence was adequate in $92.75 \%(n=371)$ of patients in the present study, and this is similar to a study conducted by Kalaiselvi Selvaraj et al where they revealed a greater level of medication adherence in $95.6 \%$ of patients ${ }^{3}$. Only $38 \%$ of patients followed good dietary behaviour in the present study, which is similar to a study done by Sasi ST et al [18]. Several studies suggest that diet is an effective factor in controlling, and improving the quality of life in T2DM [19,20]. Diabetic patients worldwide are routinely instructed to adopt a healthy eating behaviour, that demanded adjustments in food habits, beliefs and meal patterns on a long-term basis [21]. We found that $68.5 \%(n=274)$ patients participated in our study had done regular exercise, which is comparatively better to the study done by Suguna A et al in a rural area of Bangalore district[22]. A study done by Dagmawit Tewahido et al reported that almost all participants accepted that they doesn't exercise daily. The most commonly given reasons for not performing daily physical exercise were busy work schedule, lack of motivation, lack of interest, not being able to bear gymnasium expenses and not convinced that exercise is important[23]. Adherence to exercise has been reported to be very poor typically in developing countries[24]. In the present study, Foot care was found to be lowest of all domains, only $1.5 \%(n=6)$ patients were taking care of their feet, which is similar to the study $(8.6 \%)$ done by Kalaiselvi et al. This could be due to lack of appropriate understanding of its usefulness by patients with diabetes ${ }^{3}$. Patients with DM have remarkably higher risk of developing diabetic foot that can only be prevented by building awareness regarding footcare[25].

A significant positive correlation was found between age and SDSCA score that is increase in age showed better self-care practices which is similar to a study conducted by Viji P.T et al[26], Zanetti et al[27] Xu and Pan et al [28]. In this study level of education was an influencing factor in self-care activities which means that patients with higher education had better self-care than others. These findings are identical to the studies conducted by Nazila et al [29], karters et a[[30], connells et al[31], and vosoghis et al[32] study. A study conducted by 
Idongesit reported that patients having higher educational level (and hence of higher SES) have a higher chance of acquiring knowledge from the internet, mass media and books. In addition, they have fewer difficulties in communicating with the health care professionals, and may have a good grasp of information [33]. Low education level may lead to inadequate self-management practices, lower self-efficacy and lower continuity care. Steps to upgrade literacy level would be a cost effective strategy to minimize morbidity and mortality associated with diabetes [34]. From our study it was also found that income had significant positive correlation with total self-care activities. A study conducted by Chio et al reported that high income was correlated with high self-care ability or low income was related with low self-care ability. The higher the income the more they take care of themselves[35]. Higher socio-economic status showed significant positive correlation with self-care activity, this was parallel to the study conducted by Veerkumar et al[36] $(0.008,9.596)$.

Domain wise correlations with study variables were also done. The total diet score was found to have a significant positive correlation with education which is similar to a study conducted by Mayur Patel et al in which secondary level of education had significant association with consumption of diabetic diet among T2DM subjects[37]. Total foot care score had a significant positive correlation with education. Various studies reported that diabetic foot care had significant association with the level of education and diabetic foot care knowledge[38,39,40,41]. A study conducted by Mira $\mathrm{M}$ et al also reported a significant association between educational level with the extent of diabetic foot care knowledge and practice ( $\mathrm{p}=0.001,0.02$ respectively) ${ }^{[42]}$.

\section{CONCLUSION}

In conclusion the present study has demonstrated that the self-care practices of diabetic patients in the current setting is average $(53.75 \%)$. Most of the patient had poor foot care practice (98.5\%) and inadequate physical activity (68.5\%). Medication adherence (92.75\%) and blood glucose monitoring within the past 3 months $(100 \%)$ was found to be followed by almost all patients. Self-care practice were found to have significant correlation with the age, education, SES. The study suggest that educational interventions needs to be done emphasising the importance of foot care and physical activity.

\section{ACKNOWLEDGEMENT}

We explicit our heartfelt gratitude to our Principal, H.O.D and Faculties of Pharmacy Practice Department, K.L.E College of Pharmacy for their invaluable support and guidance.

\section{CONFLICT OF INTEREST}

There was no conflict of interest among the authors.

\section{REFERENCES}

1. Mohan H. Diabetes Mellitus. In: Mohan P, Mohan T, Mohan S, Textbook of Pathology. 2015; 7th ed:808.

2. Organization (WHO) WH. Definition, diagnosis and classification of diabetes mellitus and its complications: World Health Organization (WHO)2007.

3. Selvaraj K, Ramaswamy G, Radhakrishnan S, Thekkur P, Chinnakali P, Roy G. Self-care practises among diabetes patients registered in a chronic disease clinic in Puducherry, South India. J of social health and diabetes 2016; 4(1):25-29.

4. Tuomilehto J, Lindstrom J, Eriksson JG, Valle TT, Hamalainen H, Ilanne-Parikka P, Kaeinanen-Kiukaanniemi S, Laakso M, Louheranta A, Rastas M, Salminen V, Uusitupa M., N . Engl. J. Med., 2001; 344:1343.
5. American Diabetes Association. Lifestyle management. Sec. 4. In Standards of Medical Care in Diabetes-2017. Diabetes Care 2017; 40(Suppl. 1):S33-S43

6. Understanding Diabetes \& Self Care guideline. Understanding Diabetes Mellitus: https://www.worlddiabetesfoundation.org

7. Front . Endocrinol., 09 June 2017https://www.frontiersin.org

8. Wangoo SK, Maji D, Das AK, Rao PV, Moses A, Sethi B, et al. Barriers and solutions to diabetes management: An Indian perspective. Indian J Endocrinol Metab 2013; 17:594-601.

9. Improving the sustainability of healthcare systems through better adherence to therapies: a multi-stakeholder approach: background briefing. http://www.eupatient.eu/globalassests/policy/adherence-complianceconcordance/adherence---joint-briefing-paper.pdf

10. DiMatteo MR. Variations in patients' adherence to medical recommendations: a quantitative review of 50 years of research. Med Care 2004. March; 42(3):200-209.

11. William SA. Making diabetes Education Accessible for people with Visual impairment. Diabetes edu. 2009; 35(4):612-21.

12. Veerakumar A M, Shanmugapriya D, Shanmugapriya J, Soorya Narayanan B, Subashini S. Self-care Activities among Diabetic patients in rural areas of Trichy District, Tamil Nadu. NJRCM. 2017; 6(2):120-123.

13. AADE. AADE7 self-care behaviours. Diabetes Educ 2008; 34:445-9.

14. Jackson IL, Adibe MO, Okanta MJ, Ukwe CV. Knowledge of selfcare among type 2 diabetes patients in two states of Nigeria. Pharmacy Practice 2014 Jul-Sep; 12(3):404.

15. Reyes J, Tripp-Reimer T, Parker E, Muller B, Laroche H. Factors Influencing Diabetes Self-Management Among Medically Underserved Patients With Type II Diabetes. May 2017; 4:1-13

16. Toobert DJ, Hampson SE, Glasgow RE: The summary of diabetes self-care activities measure: results from 7 studies and a revised scale. Diabetes Care 2000; 23:943-950.

17. Nejaddadgar N, Solhi $M$, Jegarghosheh $S$, Abolfathi $M$, Ashtarian H. Self-Care and Related Factors in Patients with Type 2 Diabetes. Asian J Biomed Pharmaceut Sci. 2017; 7(61):6-9.

18. Sekhar STVD, Kodali M, Burra CK, Muppala SB, Gutta P et al. Self-care activities, Diabetes distress and other factors which affected the glycemic control in a tertiary care teaching Hospital in South India. J of clinical and diagnostic research 2013; 7(5):857-60.

19. Predicting dietary practice behaviour among type 2 diabetics using the theory of planned behaviour and mixed methods design. Int J Biol LifeSci. 2012; 11-25.

20. Zoellner J, Estabrooks PA, Davy BM, Chen YC, You W. Exploring the Theory of Planned Behaviour to Explain Sugar-sweetened Beverage Consumption. J Nutri Edu Behav. 2012; 44:172-7.

21. M.I. Harris, "Frequency of Blood Glucose Monitoring in Relation to Glycemic Control in Patients with Type II diabetes," Diabetes Care,Vol.24, no.6, pp.979-982,2001.

22. Suguna A, Magal SA, Stany A, Sulekha T, Prethesh K. Evaluation of self-care practices among diabetic patients in a rural area of Bangalore district, India.Int.J.Curr.Res.Aca.Rev 2015; 3(6):415422.

23. Tewahido D, Berhane Y. Self-Care Practices among Diabetes Patients in Addis Ababa. J PLoS One 2017; 12(1):1-10.

24. Prabhu SS, Ramya N. Non-adherence to diabetic treatment and its effect on glycaemic control, study at a rural hospital of Tiruchirappalli, Tamilnadu, India. The Internet Journal of Health. 2011; 2(2).

25. Lakshmi N, Ptel N, Parmar P, Garasiya K, Chaudhary M. Study the foot care practice among diabtetes patients in Ahmedabad city, Gujarat. Int J of med science and public health 2018; 7(5):333-37

26. Viji P T, Singh M. A Study to Assess the Practice of Diabetic Patient towards Self Care Activities for Longevity of Life. Sch. J. App. Med. Sci.2014; 2(1A):57-60.

27. Zanetti M, Baquedano I, Martins T,santos M. Self-Care of patients with Diabetes Mellitus Cared for at an Emergency Service in Mexico. Rev Latino-Am, Enfermagem 2010; 18(6):1195-202.

28. $\mathrm{Xu} Y \&$ Pan W. Self-management practices of Chines Americans with type 2 diabetes. Nursing and Health Sciences 2010; $12: 228-34$. 
29. Raithatha JS, Shankar US, Dinesh K. Self-Care Practices among Diabetic Patients in Anand District of Gujarat. ISRN Fam Med. 2014. http://dx.doi.org/10.1155/2014/743791.

30. Nejaddadgar N, Solhi M, Jegarghosheh S, Abolfathi M, Ashtarian H. Self-Care and Related Factors in Patients with Type 2 Diabetes. Asian J Biomed Pharmaceut Sci. 2017;7(61):6-9.

31. Karter AJ, Ferrara A, Darbinian JA, Ackerson LM, Selby JV. Selfmonitoring of blood glucose: Language aid financial barriers in a managed care population with diabetes. Diabetes Care.2000; 23:47-483.

32. Connell M, Michael C, Nancy S, AnitaS, Erika F. Self-care behaviours in indigent patients with heart failure. Eur J Cardiovasc Nurs. 2008; 23:223-30.

33. Vosoghi Karkazloo N, Abootalebi Daryasari Gh. The study of self-care agency in patients with diabetes. Quarterly J Berjand. 2009;8:197-204.

34. Jackson IL, Adibe MO, Okanta MJ, Ukwe CV. Knowledge of selfcare among type 2 diabetes patients in two states of Nigeria. Pharmacy Practice 2014 Jul-Sep; 12(3):404.

35. Kassahun T, Gesesew H, Mwanri L, Eshetie T. Diabetes related knowledge, self-care behaviours and adherence to medications among diabetic patients in Southwest Ethiopia: a cross- sectional study. BMC Endocrine Disorders. 2016; 16(28):1-11.
36. Chiou C, Bai Y, Chang Y. Self-care behaviour and related factors in older people with type 2 diabetes. J of Clinical Bursing 2009; 18:3308-15.

37. Veerakumar A M, Shanmugapriya D, Shanmugapriya J, Soorya Narayanan B, Subashini S. Self-care Activities among Diabetic patients in rural areas of Trichy District, Tamil Nadu. NJRCM. 2017; 6(2):120-123.

38. Patel M, Patel MI, Patel MY, Rathi KS. A Hospital-based observational study of Type 2 Diabetic subjects from Gujarat India. Health popul NUTR. 2011; 29(3):265-72.

39. Hasnain S, Sheikh NH. Knowledge and practices regarding foot care in diabetic patients visiting diabetic clinic in Jinnah Hospital, Lahore. J Pak Med Assoc. 2009; 59(10):687-90.

40. Desalus 00, Salawu FK, Jimoh AK, Adekoya AO, Busari OA, Olokoba AB. Diabetic foot care: Self-reported knowledge and practice among patients attending three tertiary hospitals in Nigeria. Ghana Med J. 2011; 45(2):60-65.

41. Chellan G, Srikumar S, Varma AK, Mangalanandan TS, Sundram KR, Jayakumar RV, Bal A, Kumar H. Foot care practice- The key to prevent diabetic foot ulcers in India. Foot(Edin). 2012; 22(4):298-302.

42. Lamchahab FZ, El Kihal N, Khoudri I, Chraibi A, Hassam B, Ait Ourhroui M. Factors influencing the awareness of diabetic foot risks. Ann Phys Rehabil Med. 2011; 54(6):359-65. 